\title{
Measurement of Cognitive Growth Factors of Regional Economy Based on Panel Data
}

\author{
Kadochnikova, E. I. \\ Ismigilov I.I.
}

Kazan Federal University, Institute of Management, Economics and Finance, Kazan, 420008, Russia

\section{Doi:10.5901/mjss.2014.v5n24p377}

\section{Abstract}

The article seeks to demonstrate the need for improved mesoeconomical measurement by separating the sphere of production and dissemination of knowledge and formulate an approach to the measurement of cognitive factors in the economic growth of the regional economy. This suggests presenting a classification of growth factors, theoretical principles of knowledge management, knowledge base and the methods of multivariate data analysis: crossed classification and panel data. The study intends to provide a method for measuring changes in the economy of the region under the influence of new knowledge by means of an econometric analysis of the knowledge indicators system - predictors of the cognitive factors of economic growth in the region. The author applies a multidisciplinary approach to the study, carrying out a synthesis of scientific publications on the problems of economic growth, knowledge management, and accumulation of knowledge in the information space of the region, applied analysis. It is emphasized that there is the need for multivariate statistical methods in the analysis of stochastic information. It is proposed to measure and simulate the spatial heterogeneity of the innovation economy based on panel data. The article stresses the need for and the importance of measuring cognitive growth factors for the innovation regional economy. The result is a methodical approach to the calculation of integral indices on the basis of a system of knowledge indicators in the regional economy. The article presents the more conceptual judgments and general recommendations. Therefore, future studies can perform more detailed calculations and experimental development. The presented methodical approach can be useful for improving the monitoring in the system of the state strategic planning to increase the efficiency of innovation and gain competitive advantages of the region's economy.

Keywords: economic growth, knowledge management, innovations, regional economy, models of panel data, integral index.

\section{Introduction}

\subsection{New knowledge as a source of competitive advantage}

The most important strategic resource in today's innovation economy is information; as knowledge is useful information, transformed into the ability to act effectively (Harrington, 2008). Information and knowledge are what many corporations increasingly manufacture, sell and acquire. It is emphasized that innovation as the ability of corporation to continuously innovate, what entails important organizational outcomes (Galunic and Rodan, 1998; Quintane et al., 2011), is determined by the creation, distribution, and the embodiment of new knowledge into products and services. Therefore, the information and knowledge embodied in products and services are the most important result of industrial activity, the primary source of value (Grant, 1993; Drucker, 1995) and sustainable competitive advantage (Nonaka, 1991) of not only one individual corporation, but also a separate economic activity, sector, region and the country as a whole.

\subsection{Cognitive growth factors}

Modern growth theories focus on the study of endogenous, monetary, institutional and technological factors of economic growth (Barro, 1997; Jones and Charles,1999; Grigoreva and Fesina, 2014). In this case the assumption of constant technology levels in the neoclassical production function $F(K, L, T)(B a r r o, 1997)$ is weaker nowadays. The role of knowledge as an endogenous factor of economic growth determines the need to improve the quantification and applied analysis of innovation primarily by improving the mesoeconomic dimensions. The endogenous nature of knowledge determines the feasibility of defining the separate classification group of growth factors - cognitive factors. Therefore, in order to improve the monitoring in the system of the state strategic planning (Naveh et al., 2012; Ismagilov I., 2012; Zarova and Musikhin, 2013) for the measuring and modeling of the interaction between qualitative and quantitative cognitive factors of production activities with the parameters of economic growth and the dynamic equilibrium of the 
regional socio-economic system the system of knowledge indicators can be used in the context of economic activities, sectors and regions.

\subsection{The system of regional accounts as a knowledge management system in the mesoeconomics}

Based on the classification criteria of knowledge (Nonaka and Takeuchi, 1995; Polanyi,1966; Eck, 1998; Bounken, 2004), the system of regional accounts for the quantitative description and analysis of the generalizing results of economic development is a complex control system of mesoeconomic knowledge and information base of cost knowledge indicators. The system of regional accounts is a direct tool for managing the lifecycle of mesoeconomic knowledge: knowledge creation - the accumulation of knowledge - knowledge transfer - the dissemination of knowledge - the application of knowledge - new knowledge creation and removal of obsolete knowledge, and creates a field of interaction between activities, sectors and knowledge. Despite the large number of scientific publications in the field of corporate knowledge, the problems of knowledge management and knowledge-based management in the mesoeconomics are hardly studied. The problem of production and dissemination of knowledge was investigated in the middle of the last century by the example of the United States economy (Machlup, 1966): the economic aspects of the production and dissemination of knowledge were studied and the costs and number of employees in five groups of economic activities (research and development, education, mass communication, information technology, information services), called "the sphere of production and dissemination of knowledge", were measured. It should be noted that this definition does not have a unique interpretation; it is not defined in the Standard of the System of National Accounts (The System of National Accounts, 2008). However, the main function of corporations - to integrate knowledge into goods and services in order to obtain a competitive advantage (Grant, 1993; Drucker, 1995; Nonaka, 1991) greatly expands the boundaries of this sphere. In our opinion, it is the sphere of production of goods and services as a whole, which carries out the integration of information resources, ideas and experience of the corporation staff, social interaction, and innovation - new knowledge.

\section{Materials and Methods}

The author used the materials of scientific publications and the official collections of the state statistics services. The researcher generated the development goals of the innovation economy and the methods of multivariate data analysis in order to develop approaches for measuring cognitive endogenous growth factors.

\section{Results and Discussion}

\subsection{Analysis of multidimensional data by crossed classification}

The analysis of multidimensional data in general is to solve two problems: reducing the dimensions and studying the relationship between the characteristics of all the sample objects. The problem of multidimensional data analysis was called "statistics $-\bar{p}_{i j}$ " in the 70-s of the XX century. In a study (Rabinowitz, 1973) the method of crossed classification of the statistical elements of the set by the average value was proposed, where the set is divided into groups according to the factors of direct action and into subgroups according to the factors of the reaction on the analyzed efficiency index. The specificity of the method of multidimensional groups where productive efficiency index presents the statistical function of the average relationship $\left(\bar{p}_{i j}\right)$ between production factors is proved by the author with the help of correlation and regression analysis methods. In the study (Rabinowitz, P., 1973) the following regression equation is proposed:

$\bar{Y}_{\left(\Sigma \frac{x_{i j}}{\bar{X}_{j}}\right)}=a_{0}+a_{1} \sum \frac{X_{i j}}{\bar{X}_{j}}$

There is a modified classical system of normal equations to determine the parameters of the regression:

$\left(n a_{0}+a_{1} \sum \bar{X}_{\bar{X}_{i j}}=\sum Y\right.$,

$a_{0} \sum \frac{X_{i j}}{\bar{X}_{j}}+a_{i} \sum\left(\frac{X_{i j}}{\bar{X}_{j}}\right)^{2}=\sum Y \sum \frac{X_{i j}}{\bar{X}_{j}}$.

$a_{0}=\bar{Y}-j a_{1}$

By substituting the coefficient ao with the expression (3) in the second system equation we obtain:

$\left(Y-j a_{1}\right) \sum \frac{X_{i j}}{\bar{X}_{j}}+a_{1} \sum\left(\frac{X_{i j}}{\bar{X}_{j}}\right)^{2}=\sum Y \sum \frac{X_{i j}}{\bar{X}_{j}}$.

Thence 


$$
a_{1}=\frac{\sum Y \sum \bar{X}_{\bar{X}_{j}}-\bar{Y} \sum \frac{X_{\bar{X}_{j}}}{\overline{\bar{X}}_{j}}}{\sum\left(\frac{X_{i_{j}}}{\bar{X}_{j}}\right)^{2}-2 \sum \bar{X}_{\bar{X}_{j}}}
$$

After a series of transformations it is obtained:

$$
a_{1}=\frac{\sigma_{y} \sum_{x_{x-j}} V x_{j}}{\sum V x_{j}^{2}+\sum\left(2 r x_{j} x_{j+n} V x_{j} V x_{j+n}+2 r x_{j-n} x_{j+n} V x_{j-n} V x_{j+n}\right)},
$$

Where ${ }^{r_{y x_{j}}}$ is linear coefficient of pair correlation,

$V x_{j}$ - coefficient of variation.

If grouping is initiated on three factors, then

$$
a_{1}=\frac{\sigma_{y}\left(r_{y x 1} V_{x 1}+r_{y x 2} V_{x 2}+r_{y x 3} V_{x 3}\right)}{V_{x 1}^{2}+V_{x 2}^{2}+V_{x 3}^{2}+2 r_{x 1 x 2} V_{x 1} V_{x 2}+2 r_{x x 1 x 3} V_{x 1} V_{x 3}+2 r_{x 2 x 3} V_{x 2} V_{x 3}} .
$$

In the research (Rabinowitz, 1973) the feasibility of studying the relationship by crossed classification using $\bar{p}_{i j}$. model for any number of factors ( $\mathrm{n}$ ) was proved.

\subsection{Analysis of panel data}

Currently, one of the most popular tools in the econometric studies of multidimensional data is panel data analysis. Panel data consist of repeated observations of the same sample units, which are carried out in successive periods of time. Therefore, panel data combine the analysis capabilities as of time series and spatial observations. It becomes possible to consider and analyze the differences between the individual economic units that cannot be done in the framework of standard regression models. We can point to a number of advantages in using the panel data (Eliseeva, 2014):

- Panel data allow taking into account individual heterogeneity;

- Panel data provide less collinearity and more assessment efficiency;

- Panel data give an opportunity to study the dynamics of changes in the individual characteristics of units in the aggregate;

- Panel data are better able to identify and measure the effects, which are not definable only in the time series, or only in the spatial data;

- Panel data allow us to design and test more complex behavior patterns;

- Panel data make it possible to avoid the bias associated with the aggregation of data;

- Panel unit root tests have standard asymptotic distribution, in contrast to the problem of non-standard distribution.

In a class of unidirectional models the unified model assumes that the units of population have no individual differences. The fixed effects model:

$$
Y_{i_{t}}=\alpha_{i}+X_{i_{t}} \beta+\varepsilon_{i_{t}}, \alpha_{i}=z_{i} \alpha \text {. }
$$

It assumes that each unit has its own specific individual characteristics that are constant over time for each object. Its assessment was prepared using the method of least squares to the expression:

$$
\left(y_{i t}-\bar{y}_{i}\right)=\left(x_{i t}-\bar{x}_{i}\right)^{\prime} \beta+\left(u_{i t}-\bar{u}_{i}\right)
$$

If the units of the population differ in their individual characteristics, but these differences are random in nature, in this case it is better to consider a model with random effects (random effects model):

$$
Y_{i t}=X_{i t} \beta+\alpha+u_{i}+\varepsilon_{i t} \text {. }
$$

Its assessment is determined by the executable generalized method of the least squares, which weighs excesses in accordance with the structure of the covariance matrix and estimates the variance as parameters. Two-way panel data model with fixed effects in addition to the individual effects also includes time effects:

$$
Y_{i_{t}}=X_{i_{t}} \beta+\alpha_{i}+\gamma_{i}+\varepsilon_{i_{t}} \text {. }
$$

Panel data provide the investigator with a large number of observations, increasing the number of freedom degrees, reducing the dependence between the explanatory variables, and the standard errors of the estimates (Ratnikova, 2006). Panel data models enable us to trace the evolution of the individual characteristics of all the sample objects in the time. 


\subsection{System of knowledge indicators of the regional economy on the basis of panel data}

To measure cognitive endogenous growth factors the study presents a system of knowledge indicators of the regional economy. The construction of the system of knowledge indicators of the regional economy can be directed to the calculation of three integral indices:

- Integral leading index (index dynamics precedes changes in the economic development);

- Integral matching index (index dynamics coincides with changes in the economic development);

- Integral lagging index (index dynamics is behind the changes in the economic development).

The calculation of integral indexes is based on the statistical reporting indicators that characterize the innovative development of the region and are presented in Table 1.

Table 1. System of knowledge indicators of the regional economy

\begin{tabular}{|l|l|}
\hline The life cycle of knowledge & Indicators of knowledge - predictors of cognitive growth factors \\
\hline \multirow{5}{*}{ Creation } & The number of employees in research and development, th. Pers. \\
\cline { 2 - 3 } & The share of spending on research and development in the gross regional product, \% \\
\cline { 2 - 3 } & The amount spent on training and retraining, mln. Rub. \\
\cline { 2 - 2 } & $\begin{array}{l}\text { The share of organizations implementing technological, organizational and marketing } \\
\text { innovations in the reporting year, \% }\end{array}$ \\
\cline { 2 - 2 } & The number of produced advanced technologies, units \\
\hline \multirow{5}{*}{ Accumulation } & The share of the manufacturing sector in the gross value added, \% \\
\cline { 2 - 2 } & Investments in fixed assets, mln. Rub. \\
\cline { 2 - 2 } & The volume of innovative products and services, mln. Rub. \\
\cline { 2 - 2 } & The expenditure on technological innovation of the organizations, mln. Rub. \\
\cline { 2 - 2 } & Special costs associated with environmental innovations, mln. Rub. \\
\hline \multirow{2}{*}{ Exchange process } & Provision of information and communication technologies \\
\cline { 2 - 2 } & The number of personnel engaged in research and development, th. Pers. \\
\hline \multirow{5}{*}{ Application } & The amount spent on training and retraining, mln. Rub. \\
\cline { 2 - 2 } & The number of organizations engaged in research and development, units \\
\hline & The share of the manufacturing sector in the gross value added, \% \\
\cline { 2 - 2 } & The share of forwarded innovation products in the gross regional product, \% \\
\cline { 2 - 2 } & The impact of the expenditure on technological innovation, mln. Rub. \\
\hline
\end{tabular}

The selection and evaluation of indicators are carried out on the basis of theoretical and practical criteria: theoretical criteria (validity of economic theory, relevance, and appropriateness); practical criteria (frequency of publication, regularity, sufficient sample size, the stability of the calculation method).

The calculation of integral indices involves determining the weighting coefficients of the knowledge indicators included in the index. The application of the expert evaluation method (Delphi approach), widespread in practice, introduces subjectivity into the definition of weighting factors in the calculation of the integral index of the regional innovation development. Noteworthy is an approach that determines the weight of each indicator, based on the calculation of pair correlation coefficients, which represent the estimation of the closeness of the relationship between changes in performance over time (Raiskaya et al., 2009). And in the literature it is proposed to determine the weighting coefficients based on the econometric approach (Mamaeva, 2012). In the first stage indices are selected - knowledge indicators $\left(\mathrm{Y}, \mathrm{X}_{1}, \mathrm{X}_{2}, \ldots \mathrm{X}_{\mathrm{k}}\right)$. One of the selected indicators is seen as a productive indicator $\mathrm{Y}$ to construct a regression model. For each i-th region, a linear regression of the selected productive indicator for other indicators of knowledge is designed:

$$
Y=a_{0}+a_{1} X_{1}+a_{2} X_{2}+\ldots+a_{k} X_{k}
$$

To construct a regression that takes into account the individual characteristics of each region (economic activity, sector of the economy), you should use the panel data model with fixed effects. In the second phase, $\gamma_{j}$ - weighting coefficients are calculated, which show the contribution of each j-th indicator of knowledge in changing the effective index:

$$
\gamma_{j}=\frac{R_{y x_{j}} \cdot \beta_{j}}{R^{2}}, j=1, \ldots k,
$$

where ${ }^{R_{y x_{j}}}$ is coefficient of pair correlation between factor $\mathrm{X}$ and the dependent variable $\mathrm{Y}, R^{2}-$ coefficient of 
determination of the constructed model, ${ }^{\beta_{j}}$ - standardized regression coefficient, which is determined by the indicators of

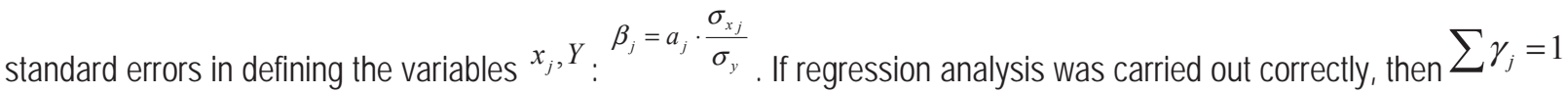
- The weighting factor for $Y$ is set equal to unity. At the third stage the integral index for the $i$-th region (economic activity, sector of the economy) is calculated by the formula:

$$
I_{i}=\sum_{j=0}^{k} \gamma_{j} \cdot \frac{x_{i j}}{\max x_{i j}}
$$

Where $x_{i j}$ is the value of $j$-th knowledge indicator for the $\mathrm{i}$-th object. The sample provided by panel data, is previously divided into time periods and within each of them the parameters are led to a comparable form by normalizing.

Together with dynamic indicators of knowledge it seems appropriate to measure the regional proportions for the study of spatial aspects of the innovation economy:

- Measurement of changes in the spatial structure of innovation and cognitive factors of production;

- Change of the production specialization in the aspect of regions and economic activities;

- Change of specialization in the context of the integrated economic activities (manufacturing, agriculture, etc.);

- Changes in the territorial structure of the indicators of human capital and innovative capacity across regions and economic activities.

Measuring and modeling of spatial heterogeneity of innovation can be accomplished by constructing a group of econometric panel data models in the sections: the production of knowledge in the regions; the dissemination of knowledge in the regions; the results of development of the production sphere and dissemination of knowledge.

\section{Conclusion}

The author set out the method of multidimensional groups applying relations to the average, and a panel data model with fixed effects, for which estimation the deviations from the average are used. These methods make it possible to identify the influence of signs-factors taking into account the individual heterogeneity of the sample objects. The use of these multivariate methods of the applied analysis enable to measure and model the changes in the level of economic development of the region under the influence of new knowledge. Based on these methods, the proposed system of knowledge indicators, which is conceptually outlined in this article, is necessary for strategic planning and decisionmaking in the management to improve the efficiency of innovation. The application of econometric approach in the construction of the integral index allows you to have a reliable and efficient tool for differentiation of innovative development of the regions. Definition of cognitive factors of economic growth as a classification feature in the methodology of mesoeconomic measurements will make it possible in the future studies to model the trend of economic development in the light of innovation activities and analyze the effectiveness of innovation in the region.

\section{References}

Barro, R. J., 1997. Macroeconomics. Cambridge, MA: MIT Press, pp: 87-135.

Bounken, R., 2004. The structure of organizational knowledge in virtual enterprises. Problems of the theory and practice of management, 6: $77-84$.

Drucker, P. F., 1995. The new society of organizations. Harvard Business Review. Vol. 22, 5: 95-104.

Eck, K., 1998. Knowledge as a new paradigm of management. Problems of the theory and practice of management, 2: 68-73.

Eliseeva, I., 2014. Econometrics. Yurait, Moscow, pp: 371-373.

Galunic, C. and Rodan, S., 1998. Resource recombination in the firm: knowledge, structures and the potential for Schumpeterian innovation. Strategic Management Journal, Vol. 19,12: 1193-1201.

Grant, R. M., 1993. Towards a knowledge-based theory of the firm. Strategic Management Journal, Winter Special Issue, 17: $109-122$.

Grigoreva, E., Fesina, E., 2014. Economic Security as a Condition of Institutional Support of Economy Modernization. World Applied Sciences Journal, 31 (5): 940-948.

Harrington, J., 2008. Perfection of knowledge management. RIA "Standards and Quality", Moscow, pp: 41, 45.

Ismagilov I., 2012. Strategic management of development of the enterprise in the conditions of formation of network economy. Kazan economic messenger, 1:16-18.

Jones, Charles I., 1999. Growth: With or Without Scale Effects. American Economic Review, 89:139-144.

Machlup, F., 1966. The production and dissemination of knowledge in the United States. Progress, Moscow, pp: 459

Mamaeva, Z., 2012. Evaluation of regional development: an econometric approach. Bulletin of the Nizhny Novgorod N. I. Lobachevsky University, 2 (2): 202-208.

Naveh, M.H., Torosyan, T., Jalaee, S.A., 2012. Regional Economic Integration and its Effects on Economic Growth and Economic 
Welfare. World Applied Sciences Journal, 17 (10): 1349-1355.

Nonaka, I., 1991. The knowledge-creating company. Harvard Business Review. Vol. 69, 6: 96-105.

Nonaka, I., Takeuchi, H., 1995. The knowledge - creating company. How Japanese companies create the dynamics of innovation. Oxford University Press. New York. Oxford. pp. 82-99.

Polanyi, M., 1966. The Tacit Dimension. Routledge\&Kegan Paul, London, pp.167.

Quintane, E., Casselman, R. M., Reiche, B. S., Nylund, P. A., 2011. Innovation as a knowledge-based outcome. Journal of Knowledge Management, Vol. 15, 6: 928-947.

Rabinowitz, P., 1973. Economic analysis by the method of multidimensional groups. Economics of Agriculture, 9: 60-64.

Raiskaya N., Sergienko, J., Frankel, A., 2009. The use of integral indices in the analysis of cyclical changes in the Russian economy. Statistical Issues, 12: 8-12.

Ratnikova, T., 2006. Introduction to the econometric analysis of panel data. HSE Economic Journal, 2: 267-316. The System of National Accounts, 2008. URL: http://unstats.un.org/unsd/nationalaccount/docs/SNA2008Russian.pdf

Zarova, E., Musikhin, S., 2013 Operative monitoring of the socio-economic development of the subjects of the Russian Federation in the system of the state strategic planning. Statistical Issues, 4: 16-21. 